\title{
THE STUDY OF CLEFT LIP AND PALATE IN NORTH KARNATAKA REGION
}

\section{Dinanath Pujari ${ }^{1}$, Sundip Charmode ${ }^{* 2}$, HS Kadlimatti ${ }^{3}$.}

${ }^{1}$ Associate Professor, Department of Anatomy, ESIC Medical College Kalaburagi, Karnataka, India.

${ }^{* 2}$ Assistant Professor, Department of Anatomy, ESIC Medical College Kalaburagi, Karnataka, India.

${ }^{3}$ Professor, Department of Anatomy, ESIC Medical College Kalaburagi, Karnataka, India.

\section{ABSTRACT}

Background: A cleft occurs when certain body parts and structures do not fuse together during fetal development. Clefts can involve the lip and/or the roof of the mouth (palate). There are varying opinions on the actual incidence of clefts. Some experts say that the highest cleft incidences are among Asians. As there are very few studies regarding the incidence of cleft lip and palate in North Karnataka, this study was conducted.

Materials and Methods: The data was collected from the patients of the hospital of ESIC Medical College Kalaburagi, Karnataka, India.

Result: The occurrence of cleft lip was more compared to, in combination with cleft palate and cleft palate alone. The exact cause of cleft lip and palate is not known but most experts agree that the causes of cleft lip and/or palate are multifactorial and may include a genetic predisposition, as well as environmental or nutritional factors. In this study the type of malformation, the difference in the gender of patients, the parental age during marriage and the consanguineous marriage are studied in detail. The Malformations were more on the left side compared to right side. This anomaly was observed more in male patients than female patients.

Conclusion: As the parental age is one of the predisposing factor. In this study the age of parents was found less than Twenty years in most of the cases. The consanguineous marriage is also considered as one of the risk factor, this study found that most of the parents had consanguineous marriage.

KEY WORDS: Consanguinity, Cleft Lip, Cleft Palate.

Address for Correspondence: Sundip Charmode, Department of Anatomy, Assistant Professor, ESIC Medical College Kalaburagi, Karnataka, India. E-Mail: sundip.charmode@yahoo.com

Quick Response code

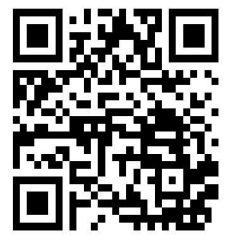

DOI: 10.16965/ijar.2018.396
Journal Information

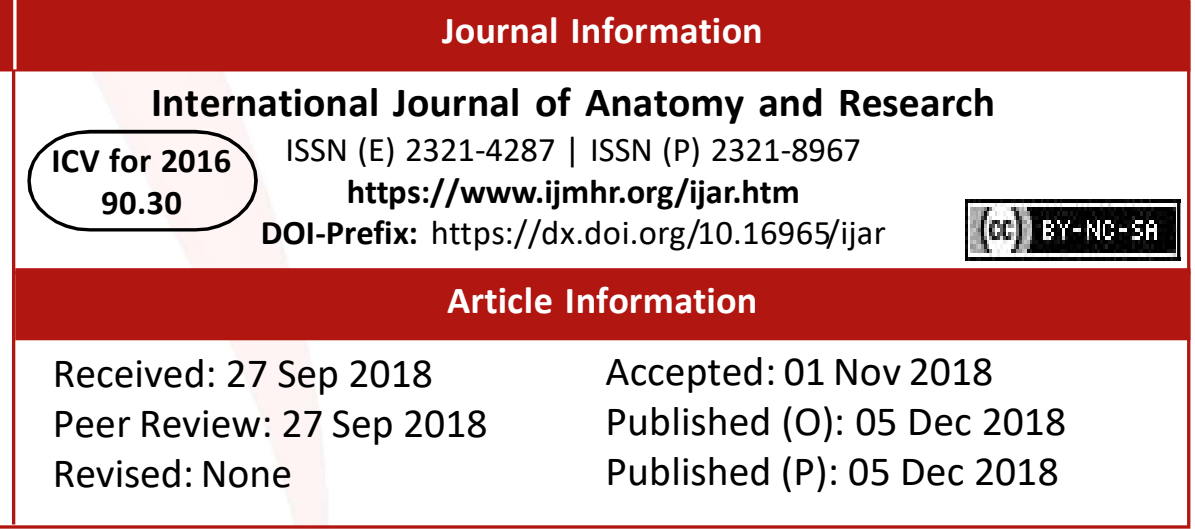

\section{INTRODUCTION}

The face is develops from five different processes, which meet in the midline to complete the process in development of face. The failure of meeting of these processes results into various orofacial anomalies. Among these, cleft lip and cleft palate (CLP or cleft lip/palate) are most common. The word 'cleft' means split or fissured. CLP can occur in isolation or in combination as syndromes due to broad range of chromosomal, Mendelian or teratogenic causes. The etiogenesis attributed for CLP are, Genetic factors, consanguinity, increased maternal age, tobacco chewing, anticonvulsant drugs consumption of alcohol during pregnancy, etc.

In India, the second most populated country in the world, the birth prevalence of clefts is somewhere between 27000 and 33000 per year. There is an existing lacunae in the available literature regarding this condition in northern region of 
Karnataka, which is considered to be backward area. This was the driving force for undertaking the present study. This study was conducted to assess the influence of various factors like gender, parental age at marriage,influence of socio-economic factors and association of consanguineous marriage in parents of such patients of this region [1].

\section{MATERIALS AND METHODS}

The study was conducted at ESIC Medical College and hospital Gulbarga, located in north Karnataka region. The clinical data required for this study was collected from patients who were admitted at ESIC Hospital, Kalaburagi.

The study was approved by the Institutional Ethics Committee (IEC) of ESIC Medical College, Gulbarga, and Karnataka.

The detailed information is collected which includes history and age of patients, (possible Risk factors), Demographic status, Socio/ Economic status, parental age at marriage, Family history and marital status of parents of such patients.

All the information collected from the patients was analyzed statistically in accordance with the study parameters laid down at the onset of the study.

The data was analysed by using software SPSS 22 version. All the proportions were analysed.

\section{RESULTS}

\section{A total of 101 cases were studied as per the proforma.}

Out of 101 cases of cleft lip/palate, 54 were male and 47 were female The Bilateral Gender wise difference affection is very less (Table 1 ).

Table 1: Sex wise distribution of cases.

\begin{tabular}{|c|c|c|c|c|c|}
\hline \multirow{2}{*}{ Age } & \multicolumn{2}{|c|}{ Male } & \multicolumn{2}{c|}{ female } & \\
\cline { 2 - 6 } & No. & $\%$ & No. & $\%$ & Total \\
\hline$\leq 5$ & 21 & 38.89 & 33 & 70.21 & 54 \\
\hline $5--10$ & 11 & 20.37 & 8 & 17.02 & 19 \\
\hline $10--15$ & 4 & 7.41 & 1 & 2.13 & 5 \\
\hline$>15$ & 18 & 33.33 & 5 & 10.64 & 23 \\
\hline Total & $\mathbf{5 4}$ & $\mathbf{1 0 0}$ & $\mathbf{4 7}$ & $\mathbf{1 0 0}$ & $\mathbf{1 0 1}$ \\
\hline
\end{tabular}

Parent's age at the time of marriage was less than 20 years in 31 cases and it was between 21-26 years in 50 cases. In the remaining 20 cases the age was above 26 years (Table 2 ).
Table 2: Parental age at marriage.

\begin{tabular}{|c|c|c|}
\hline $\begin{array}{c}\text { Age at } \\
\text { Marriage }\end{array}$ & No. & $\%$ \\
\hline$\leq 18$ & 15 & 14.85 \\
\hline $18-20$ & 16 & 15.84 \\
\hline $20-22$ & 20 & 19.8 \\
\hline $22-24$ & 20 & 19.8 \\
\hline $24-26$ & 10 & 9.9 \\
\hline$>26$ & 20 & 19.8 \\
\hline Total & 101 & 100 \\
\hline
\end{tabular}

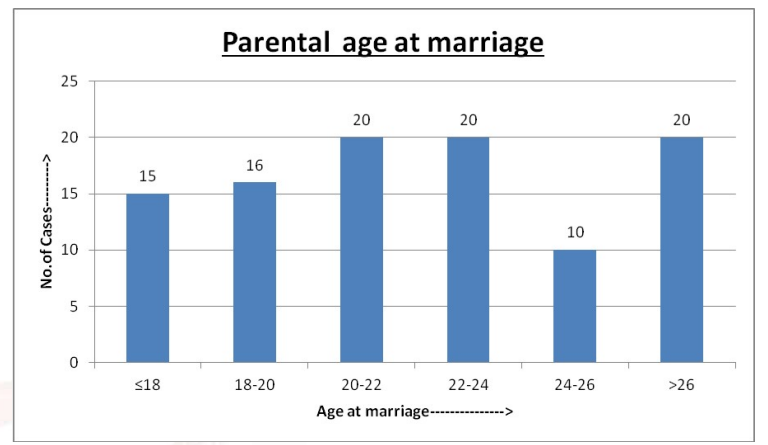

The most common condition was Cleft lip alone, which dominated the list with $83(82 \%)$ and the next was in combination with cleft palate in 11 (10.9\%). The remaining 03 cases were of isolated cleft palate (Table 3).

Table 3: Type of Anomaly.

\begin{tabular}{|c|c|c|}
\hline Anomaly & No. & $\%$ \\
\hline $\mathrm{CL}$ & 83 & 82.18 \\
\hline CL AND CP & 11 & 10.89 \\
\hline $\mathrm{CP}$ & 3 & 2.97 \\
\hline Midline CL & 2 & 1.98 \\
\hline Midline CL and CP & 2 & 1.98 \\
\hline Total & $\mathbf{1 0 1}$ & $\mathbf{1 0 0}$ \\
\hline
\end{tabular}

Types of anomalies in cases

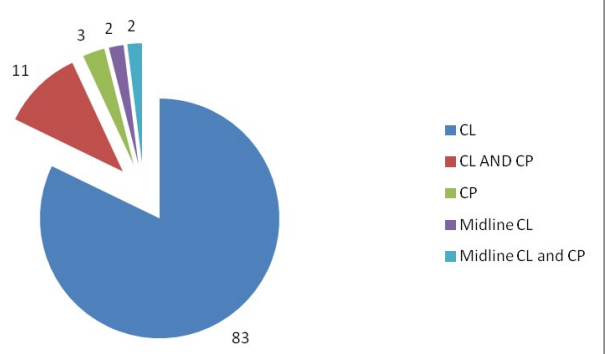

The malformations were more on left side(59.41\%), than on right side $37(36.63 \%)$ and very few in the midline 4(3.\%).

There was a significant history of consanguineous marriage in 33 cases $(32.67 \%)$ and nonconsanguinous in 68 cases $(67.33 \%)$ of parents (Table 04). Cleft lip was the most common anomaly in patients of parental consanguinity (76\%) (Table 5). 
Table 4: Anomaly in relation with consanguinity.

\begin{tabular}{|c|c|c|}
\hline & No. & $\%$ \\
\hline Consanguineous & 33 & 32.67 \\
\hline Non-Consanguineous & 68 & 67.33 \\
\hline Total & 101 & 100 \\
\hline
\end{tabular}

Table 5: Consanguinity in relation to type of Anomaly.

\begin{tabular}{|c|c|c|}
\hline Type of anomaly & Consanguinity & Percentage \\
\hline CL & 25 & $76 \%$ \\
\hline CP & 1 & $3 \%$ \\
\hline CL+P & 7 & $21 \%$ \\
\hline Total & 33 & $100 \%$ \\
\hline
\end{tabular}

Distribtion of cases with respect to consanguinity

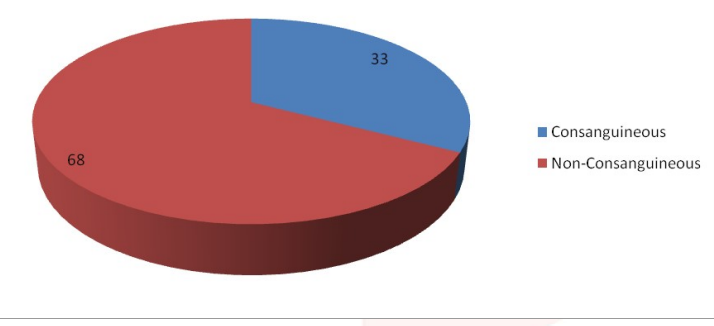

\section{DISCUSSION}

Oro-facial clefts particularly cleft lip with or without palate or cleft palate alone pose a major public health problem affecting 1 in every 500 to 1000 births worldwide. In our study, we found that majority of (82\%) patients suffered with cleft lip and meager cases with cleft palate (3\%).The study has shown that isolated cases of cleft lip dominated over all other related malformations. Even though being the most common congenital deformity, which did not have any association with other syndrome conditions. In India detailed statistical information on Cleft lip/Palate is not available, however very few studies carried out in different parts of the country suggest that the incidence of CLP ranges from 0.25-2.29 per thousand live births. ${ }^{1}$ In the neighboring country, Pakistan, Cleft lip alone dominated (42\%) compared to isolated cleft palate (24\%) and combined anomaly (34\%) [2]. In a similar study in Iran [3], patients with both deformities were found to be more prevalent than the isolated one.

Sex Distribution: The study shows that the percentage of male patients affected in our region was found to be more (53.5\%) than the females (46.5\%), which is consistent with a study done at Dharwad,South India where males dominated in all types of orofacial clefts [4] Same trend was observed in a study at sub Himalayan region [5].Similar situation is observed in Pakistan and Riyadh, however isolated cleft palate cases were seen more frequently in girls in Pakistan [2]. Contrary to this, no significant gender wise difference was found in a study carried out in Tehran. The possibility of male dominance in India is perhaps because of female feticide and negligence for the treatment of female cases. However, it could also be because of higher male to female sex ratio.

Age of the parents: It is also one of the predisposing factors. Our study found that $30 \%$ of parents' age was less than 20 years and about $20 \%$ were more than 26 years. Similar study in Tehran [3] showed that mother's age and parity were not found statistically significant in relation to cleft lip/palate and found that for this malformation mother's age was not an important factor). (A.Jamilian, F Nayeri, A Babayan). Other similar studies carried out reported that increasing maternal age has a positive influence on clefts [6-8] while some other reports showed that there is no such association with maternal age $[9,10]$. Where as an extensive study in Denmark [11] carried out on the influence of parental age, it was found that older age of both parents increased the risk of $\mathrm{CL} / \mathrm{P}$ while the incidence was less when one of the parents is in younger age group. Further it was observed that the increased paternal age influenced the causation of cleft palate and they emphasized on considering importance of paternal age not just maternal age while carrying out such analysis.

Consanguinity: Consanguinity is widely practiced in India and is prevalent in many communities. It is more prevalent in the families with low socio/economic status. In our study we found that $32.7 \%$ parents of patients were of consanguineous marriages. Cleft lip(76\%) type was commonly seen in cases of such parents.

In a study at Karaikal [12] south India it has been observed that $22.73 \%$ of parents were involved in consanguanial marriages. Further in an extensive study in three districts of Andhra Pradesh has found that consanguinity is a widely practiced ritual in Andhra Pradesh and is a major risk factor for cleft formation [13]. A retrospective case record analysis study in a 
hospital in Dharwad [4], south India has shown correlation of $47.2 \%$ patients parents with consanguinity. Consanguineous marriages are practiced not only in India but worldwide. A study in Riyadh has shown a significantly higher association of consanguinity in $56.8 \%$ patients of parents [14] while $31.8 \%$ of $C L \pm P$ infants were the result of consanguineous marriages in Iran ${ }^{3}$ and $32 \%$ of cases, in a study at Pakistan [2].

A study by Harville [15] showed that the consanguinity risk was associated with cleft lip alone, rather than cleft lip/palate and increased for babies and twins, whose parents were first degree relatives.The closed biological unions exist in consanguineous marriages, which will result in expression of autozomal recessive genes that are associated with many congenital malformations. One among them is orofacial clefts.

\section{CONCLUSION}

There is no gender wise difference observed in our study .Overall the cleft lip was the most common anomaly in patients of parental consanguinity than other or facial anomalies. The risk of association is more in parents of younger age group.

\section{Conflicts of Interests: None}

\section{REFERENCES}

[1]. Banerjee and Dhakar, CLEFT LIP AND PALATE. CIBTech Journal of Surgery Review Article 2013;2(1):45-51.

[2]. Elahi, Mohammed Mehboob.; Jackson, Ian T.; Elahi, Omar et al . Epidemiology of Cleft Lip and Cleft Palate in Pakistan, Plastic \& Reconstructive Surgery: May 2004;113(6):1548-1555.

[3]. A.Jamilian, F Nayeri, A Babayan. Incidence of Cleft lip and Palate in Tehran Journal of Indian society of pedodontics and preventive dentistry 2007;25(4):174-176.
[4]. BR Rajiv,KV Prasad and et al. The relationship between orofacial clefts and consanguineous marriages: A hospital register-based study in Dharwad,South india., Journal of Cleft Lip Palate and craniofacial Anomalies.2017;4:3-8

[5]. Dvivedi J, Dvivedi S. A clinical and demographic profile of the cleft lip and palate in Sub-Himalayan India: A hospital based study. Indian J PlastSurg 2012;45:115-120.

[6]. Womersley J, stone DH. Epidemiology of facial clefts. Arch Dis Child.1987;717-720.

[7]. Saxen I. Cleft lip and palate in Finland. parental histories, course of pregnancy and selected environmental factors. Int. J Epidemiology.1974;3:263270.

[8]. Shaw GM, Croen LA, Curry CJ. Isolated oral cleft malformations: associations with maternal and infant characteristics in a California population.Teratology.1991;43:225-228.

[9]. Viera AR, Orioli IM, Murray JC. Maternal age and oral clefts : A reappraisal. Oral Surg Oral Med Oral Pathol Oral Radiol Endod. 2002;94: 530-535.

[10]. Baird PA, Sadovnick AD, Yee IM. Maternal age and birth defects: A population study.1991;337:527-530.

[11]. Camilla Bille, Axel Skytthe and et al, CLEFT LIP AND PALATE. Epidemiology, 2005May; 16(3); 311-316.

[12]. K.Geethpriya and T Marie,IADR world congress on Preventive Dentistry, 2017

[13]. Reddy SG, Reddy RR, Sailer HF, Berge SJ. Incidence of cleft lip and palate in the state Andhra Pradesh, South India. Indian J PlastSurg 2010;43(2):184-189.

[14]. Ravichandran K, et al. Consanguinity and occurrence of cleft Lip/Palate, A hospital based- registry study in Riyadh. American Journal of Medical Genetics Part A., 2012;158A(3):541-546.

[15]. Harville EW, Wilcox AG, Lie RT, Vindenes $H, A$ byholm F. Cleft lip and palate versus cleft lip only: Are they distinct defects? Am J Epidemiol 2005;162:448-53.

How to cite this article:

Dinanath Pujari, Sundip Charmode, HS Kadlimatti. THE STUDY

OF CLEFT LIP AND PALATE IN NORTH KARNATAKA REGION. Int J Anat Res 2018;6(4.3):6014-6017. DOI: 10.16965/ijar.2018.396 